- Original Article

\title{
Clinical Characteristics and Metabolic Health Status of Obese Korean Children and Adolescents
}

\author{
Sunyoung Chun', Saerom Lee', Hyo-Jae Son ${ }^{2}$, Hye-Mi Noh', Hye-Young Oh', Han Byul Jang ${ }^{3}$, Hye-Ja Lee', \\ Jae-Heon Kang ${ }^{4}$, Hong-Ji Song ${ }^{1}$, Yu-Jin Paek ${ }^{1}$, Kyung-Hee Park ${ }^{1, *}$ \\ 'Department of Family Medicine, Hallym University Sacred Heart Hospital, Anyang, Korea \\ ${ }^{2}$ Department of Family Medicine, Kangdong Sacred Heart Hospital, Seoul, Korea \\ ${ }^{3}$ Division of Metabolic Disease, Center for Biomedical Science, Korea National Institute of Health, Cheongju, Korea \\ ${ }^{4}$ Department of Family Medicine, Obesity Research Institute, Inje University Seoul Paik Hospital, Seoul, Korea
}

Background: This study aimed to determine the prevalence of metabolically healthy and unhealthy obesity (MHO and MUO, respectively) and examine the demographic, anthropometric, and lifestyle predictors of metabolic health status in Korean children and adolescents.

Methods: This study was based on data collected from the Korean Children-Adolescent Study in 2010. A total of 1,700 children ( 846 boys and 854 girls) were included in the primary cohort and classified into metabolically healthy and unhealthy groups according to factors related to the metabolic syndrome. Demographic and biochemical features were evaluated in study participants. Logistic regression estimated the odds ratios of having more fat mass among MUO compared with MHO children after adjusting for confounding factors.

Results: Mean body mass index was higher in the MUO group than in the MHO group (24.83 vs. $23.02 \mathrm{~kg} / \mathrm{m}^{2}$, respectively). The proportion of obese participants was also higher in the MUO group (59.4\%) than in the MHO group (20.7\%). MHO children were more likely to have parents with better socioeconomic status and a higher fruit and vegetable intake compared with MUO children. Higher fat mass and percent fat was associated with MUO according to multiple logistic regression analysis.

Conclusion: Fat mass and percent fat are associated with metabolically healthy phenotypes of obesity among children and adolescents.

Keywords: Obesity; Metabolically Healthy Obesity; Metabolically Unhealthy Obesity; Pediatrics; Adolescent 


\section{INTRODUCTION}

The prevalence of obesity is increasing worldwide ${ }^{1)}$ and has recently reached epidemic proportions ${ }^{2)}$ and become a global health concern, particularly in developing countries. According to a World Health Organization report in 2009, obesity is one of the five leading global risks for mortality that are responsible for raising the risk of chronic diseases, such as cancer and hypertension. It is also associated with comorbidities including dyslipidemia, type 2 diabetes mellitus, metabolic syndrome, and cardiovascular disease as it increases insulin resistance. ${ }^{3)}$

Nevertheless, not all obese individuals are at risk of developing cardiometabolic diseases. ${ }^{4-8)}$ Several studies indicate that a subset of obese people do not present typical features of obesity complications. ${ }^{2,9,10)}$ This metabolically healthy obesity (MHO) group is characterized by preserved insulin sensitivity ${ }^{11,12)}$ and may exist in the absence of obesity-related metabolic disorders. The definition of MHO remains controversial, and no clear criteria have been globally accepted. ${ }^{3,13,14)}$ Despite the heterogeneity of methods used to define MHO, there are noticeable clinical aspects related to most adult MHO patients, such as a favorable metabolic profile ${ }^{15)}$ (preserved insulin sensitivity, normal lipid profile, normal arterial blood pressure, etc.) compared with metabolically unhealthy obesity (MUO) patients.

The obesity of childhood and adolescence has universally grown along with that of the adult population. ${ }^{16)}$ The epidemic of pediatric obesity is followed by increased rates of associated metabolic complications such as pediatric type 2 diabetes mellitus and metabolic syndrome. ${ }^{1,17)}$ In the opinion of several studies, the documented prevalence of MHO varies, ranging from $6 \%$ to $36 \%$ in pediatrics. ${ }^{18)}$ However, studies on $\mathrm{MHO}$ are mostly from data of adult populations, and research focused on MHO of children has been limited until now. In Canada, a cross-sectional study was conducted with 8- to 17-year-olds whose body mass index (BMI) was at or above the 85th percentile and who were enrolled in a multidisciplinary pediatric weight management clinic from 2005 to $2010 .{ }^{19)}$ They found that up to one in three children with obesity can be classified as MHO. The Bogalusa Heart Study examined 1,098 individuals, both children (aged 5-17 years) and adults (aged 24-43 years), between 1997 and 2002 in Bogalusa, Louisiana. ${ }^{20)}$ It showed that the MHO phenotype started in childhood was more likely to continue into adulthood. However, papers on pediatric MHO in Korea have been rarely published. Therefore, the purpose of this study was to identify clinical characteristics on MHO of Korean children and adolescents.

\section{METHODS}

\section{Subjects}

We conducted a cross-sectional analysis of childhood obesity using data from the Korean Children-Adolescent Study (KoCAS). KoCAS is an annual cohort study of school-age children and adolescents in Seoul and Gyeonggi Province in Korea that began in 2005. The overall objective of the cohort study was to identify early risk factors for obesity and associated metabolic diseases in urban Korean children. In total, 1,700 individuals were in the original cohort of students aged 8-12 years from 12 elementary schools and participated in the study in 2010. The obesity group included children whose BMI was greater than or equal to the 85th percentiles based on the age- and sex-specific BMI percentile curve of the 2007 Korean national growth charts. We included 283 overweight and obese children in the present study.

All participants and their parents/guardians provided written informed consent. Procedures for data collection were approved by the institutional review board of the Inje University Seoul Paik Hospital and the Korea Centers for Disease Control and Prevention (IRB No. SIT-2010-052).

\section{Definition of Metabolically Unhealthy Obesity}

We defined MUO as having at least two of the following five cardiometabolic risk factors: (1) waist circumference (WC) $\geq 90$ th percentile, (2) triglyceride (TG) level $\geq 110 \mathrm{mg} / \mathrm{dL}$, (3) high density lipoprotein (HDL) level $\leq 40 \mathrm{mg} / \mathrm{dL}$, (4) systolic and diastolic blood pressure $\geq 90$ th percentile, (5) fasting plasma glucose $\geq 100 \mathrm{mg} / \mathrm{dL}$. MHO was defined as having no more than one of the cardiometabolic risk factors. The cutoff values for WC and blood pressure were based on the 2007 Korean growth charts. We set the cutoff values of TG and HDL levels according to the National Cholesterol Education Program and fasting plasma glucose according to the International Diabetes Federation. We identified 150 MHO children (92 boys and 58 girls) and 133 MUO children ( 67 boys and 66 girls) by applying these criteria.

\section{Anthropometric Measurements}

Height was measured using an automatic stadiometer (DS-102; Jenix, Seoul, Korea). Weight and percent body fat were measured via bioimpedance using a body composition analyzer (BC418; Tanita, Tokyo, Japan).

BMI was computed by dividing the weight in kilograms by the square of the height in meters. The WC was measured at the midpoint between the lower border of the ribcage and the iliac crest using a nonelastic tape measure. Systolic and diastolic blood pressure was measured twice on the right arm using a mercury sphygmomanometer while the individual was resting in a seated position.

Blood tests were performed only for children whose parents had agreed to the laboratory tests and provided written informed consent in advance. After a 12-hour overnight fast, blood samples were collected from the antecubital vein into Vacutainer tubes (BD, Franklin Lakes, NJ, USA). TG and HDL cho- 
lesterol levels were measured via enzymatic assays and an autoanalyzer (model 7180; Hitachi, Tokyo, Japan). Fasting serum glucose levels were measured using the hexokinase method and a glucose analyzer (model 7180; Hitachi). Fasting serum insulin levels were measured using a radioimmunoassay kit (Diagnostic Products Co., Los Angeles, CA, USA).

\section{Questionnaire-Based Survey}

We acquired information about several factors that may influence MHO and MUO via questionnaires completed by the parents of the participants. The factors were birth weight, screen time, physical activity, fruit and vegetable intake, type of feeding in infancy, gestational weight gain of mothers, parents' height and weight, prepregnancy weight of mothers, and monthly household income.

\section{Statistical Analysis}

Participant characteristics are described using means and standard errors for continuous variables and percentages and standard errors for categorical variables. Logistic regression analysis was conducted to investigate the risk of MUO. Odds ratios and confidence intervals were estimated after adjusting for age and sex. All statistical analyses were performed using IBM SPSS ver. 22.0 (IBM Co., Armonk, NY, USA). P-values $<0.05$ were considered statistically significant.

\section{RESULTS}

The general characteristics of the study participants are presented in Table 1. Initially, we had 1,700 subjects, and after excluding those who did not meet our MHO and MUO criteria, retained 283 subjects ( 159 boys and 124 girls) as a final cohort. As shown in Table 1, 92 of 150 (61.3\%) MHO children were boys. The mean BMI was higher in the MUO group than in the MHO group ( $24.83 \mathrm{vs.} 23.02 \mathrm{~kg} / \mathrm{m}^{2}$, respectively). The proportion of obese participants was also higher in the MUO group (59.4\% vs. $20.7 \%$ in the MHO group), but there was no significant difference in the obesity status of the parents between the two groups. MHO children were more likely to have parents with better socioeconomic status and had more fruit and vegetable intake compared with MUO children.

Table 2 shows the biochemical distribution of study variables in the MHO and MUO groups. The MUO children had more fat mass and higher percent fat, but were not more likely to have higher aspartate aminotransferase, alanine aminotransferase, sodium, and total cholesterol levels compared with MHO children.

An association of fat mass with MHO is reported in Figure 1. Fat mass and percent fat were categorized into tertiles and analyzed by logistic regression. Having more fat mass or higher percent fat contributed to MUO in the unadjusted model. After controlling for confounding factors (age, sex, socioeconomic
Table 1. General characteristics of study participants

\begin{tabular}{|c|c|c|c|}
\hline Characteristic & $\begin{array}{l}\text { Metabolically } \\
\text { healthy obesity } \\
(n=150)\end{array}$ & $\begin{array}{l}\text { Metabolically } \\
\text { unhealthy obesity } \\
\qquad(n=133)\end{array}$ & P-value* \\
\hline Age (y) & $10.94 \pm 1.3$ & $11.08 \pm 1.26$ & 0.38 \\
\hline $\begin{array}{l}\text { Sex } \\
\text { Boys } \\
\text { Girls }\end{array}$ & $\begin{array}{l}92(61.3) \\
58(38.7)\end{array}$ & $\begin{array}{l}67(50.4) \\
66(49.6)\end{array}$ & 0.06 \\
\hline $\mathrm{BMI}\left(\mathrm{kg} / \mathrm{m}^{2}\right)$ & $23.02 \pm 1.89$ & $24.83 \pm 2.65$ & $<0.001$ \\
\hline $\begin{array}{l}\text { Overweight or obesity } \\
\text { Overweight } \\
\text { Obesity }\end{array}$ & $\begin{array}{r}119(79.3) \\
31(20.7)\end{array}$ & $\begin{array}{l}54(40.6) \\
79(59.4)\end{array}$ & $<0.001$ \\
\hline $\begin{array}{l}\text { Prepregnancy BMl of mothers } \\
<23 \mathrm{~kg} / \mathrm{m}^{2} \\
\geq 23 \mathrm{~kg} / \mathrm{m}^{2}\end{array}$ & $\begin{array}{r}125(86.2) \\
20(13.8)\end{array}$ & $\begin{array}{l}96(76.2) \\
30(23.8)\end{array}$ & 0.5 \\
\hline Birth weight (kg) & $3.31 \pm 0.4$ & $3.23 \pm 0.45$ & 0.1 \\
\hline Gestational weight gain (kg) & $12.63 \pm 5.5$ & $13.68 \pm 5.7$ & 0.17 \\
\hline $\begin{array}{l}\text { Feeding } \\
\text { Breastfeeding } \\
\text { Formula or mixed }\end{array}$ & $\begin{array}{r}36(24.5) \\
111(75.5)\end{array}$ & $\begin{array}{l}27(21.6) \\
98(78.4)\end{array}$ & 0.57 \\
\hline $\begin{array}{l}\text { Mother's obesity } \\
\text { Nonobese }\left(\mathrm{BMl}<25 \mathrm{~kg} / \mathrm{m}^{2}\right) \\
\text { Obese }\left(\mathrm{BMl} \geq 25 \mathrm{~kg} / \mathrm{m}^{2}\right)\end{array}$ & $\begin{array}{r}117(80.7) \\
28(19.3)\end{array}$ & $\begin{array}{r}101(78.9) \\
27(21.1)\end{array}$ & 0.7 \\
\hline $\begin{array}{l}\text { Father's obesity } \\
\text { Nonobese }\left(\mathrm{BMl}<25 \mathrm{~kg} / \mathrm{m}^{2}\right) \\
\text { Obese }\left(\mathrm{BMl} \geq 25 \mathrm{~kg} / \mathrm{m}^{2}\right)\end{array}$ & $\begin{array}{l}76(51.7) \\
71(48.3)\end{array}$ & $\begin{array}{l}80(63.0) \\
47(37.0)\end{array}$ & 0.06 \\
\hline $\begin{array}{l}\text { Sexual maturation } \\
\text { Prepubertal } \\
\text { Pubertal }\end{array}$ & $\begin{array}{r}37(24.7) \\
113(75.3)\end{array}$ & $\begin{array}{r}24(18.2) \\
108(81.8)\end{array}$ & 0.18 \\
\hline $\begin{array}{l}\text { Monthly household income } \\
\left(10^{4} \text { won/mo }\right) \\
\geq 500 \\
300-500 \\
<300\end{array}$ & $\begin{array}{l}66(45.2) \\
45(30.8) \\
35(24.0)\end{array}$ & $\begin{array}{l}34(26.2) \\
58(44.6) \\
38(29.2)\end{array}$ & 0.004 \\
\hline $\begin{array}{l}\text { Screen time } \\
\quad<120(\mathrm{~min} / \mathrm{wk}) \\
\geq 120(\mathrm{~min} / \mathrm{wk})\end{array}$ & $\begin{array}{l}95(63.3) \\
55(36.7)\end{array}$ & $\begin{array}{l}70(52.6) \\
63(47.4)\end{array}$ & 0.06 \\
\hline $\begin{array}{l}\text { Fruit and vegetable intake } \\
\text { First tertile } \\
\text { Second tertile } \\
\text { Third tertile }\end{array}$ & $\begin{array}{l}29(19.7) \\
54(36.7) \\
64(43.5)\end{array}$ & $\begin{array}{l}42(32.6) \\
54(41.9) \\
33(25.6)\end{array}$ & 0.004 \\
\hline $\begin{array}{l}\text { Physical activity } \\
<5 \text { times/wk } \\
\geq 5 \text { times/wk }\end{array}$ & $\begin{array}{l}70 \text { (47.6) } \\
77(52.4)\end{array}$ & $\begin{array}{l}74(56.9) \\
56(43.1)\end{array}$ & 0.12 \\
\hline
\end{tabular}

Values are presented as mean \pm standard deviation for continuous variables or as number (\%) for categorical variables. Sample size is unweighted. Missing data are excluded.

BMI, body mass index.

*Obtained from $\chi^{2}$ tests for categorical variables and the independent $t$-tests for continuous variables. ${ }^{\dagger}$ Both breastfeeding and formula.

status, mother's prepregnancy BMI, father's obesity, screen time, fruit and vegetable intake, and physical activity), subjects in the highest tertile of fat mass or percent fat were more likely to have MUO (OR, 14.67; 95\% CI, 5.77-37.25; OR, 10.05; 95\% CI, 4.66-21.66, respectively). These results are shown schematically in Figure 1.

\section{DISCUSSION}

Current findings from this sample of obese South Korean chil- 
Table 2. Biochemical characteristics of study participants

\begin{tabular}{|c|c|c|c|}
\hline Variable & Metabolically healthy obesity $(n=150)$ & Metabolically unhealthy obesity $(n=133)$ & P-value* \\
\hline Systolic blood pressure (mm Hg) & $117.14 \pm 14.19$ & $130.84 \pm 17.21$ & $<0.001$ \\
\hline Diastolic blood pressure $(\mathrm{mm} \mathrm{Hg})$ & $61.61 \pm 9.59$ & $69.33 \pm 12.22$ & $<0.001$ \\
\hline Waist circumference (cm) & $75.51 \pm 6.52$ & $81.15 \pm 7.54$ & $<0.001$ \\
\hline Hip circumference $(\mathrm{cm})$ & $88.64 \pm 5.83$ & $91.92 \pm 6.71$ & $<0.001$ \\
\hline Triglyceride $(\mathrm{mg} / \mathrm{dL})^{\dagger}$ & $73.22 \pm 1.56$ & $117.79 \pm 1.72$ & $<0.001$ \\
\hline High density lipoprotein cholesterol (mg/dL) & $55.64 \pm 9.61$ & $50.13 \pm 10.59$ & $<0.001$ \\
\hline Glucose (mg/dL) & $86.86 \pm 23.48$ & $84.51 \pm 7.77$ & 0.27 \\
\hline Percent fat (\%) & $31.81 \pm 5.6$ & $36.96 \pm 5.90$ & $<0.001$ \\
\hline Fat mass $(\mathrm{kg})$ & $16.39 \pm 4.69$ & $21.24 \pm 6.80$ & $<0.001$ \\
\hline Fat-free mass $(\mathrm{kg})$ & $34.68 \pm 6.47$ & $35.34 \pm 6.16$ & 0.38 \\
\hline Aspartate aminotransferase (U/L) & $24.24 \pm 9.59$ & $25.01 \pm 9.15$ & 0.48 \\
\hline Alanine aminotransferase (U/L) & $19.47 \pm 23.17$ & $24.46 \pm 19.47$ & 0.05 \\
\hline Total cholesterol (mmol/L) & $172.33 \pm 28.25$ & $177.19 \pm 27.70$ & 0.14 \\
\hline \multicolumn{4}{|l|}{ Dietary intake } \\
\hline Total calories (kcal) & $1,673.36 \pm 363.93$ & $1,687.35 \pm 348.34$ & 0.75 \\
\hline Protein $(\mathrm{g})$ & $68.48 \pm 16.85$ & $68.42 \pm 16.15$ & 0.97 \\
\hline Fat $(g)$ & $48.47 \pm 16.52$ & $49.74 \pm 15.88$ & 0.53 \\
\hline Glucose (g) & $243.71 \pm 53.97$ & $245.49 \pm 49.68$ & 0.78 \\
\hline Sodium (mg) & $4,165.54 \pm 1,254.56$ & $4,209.66 \pm 1,231.76$ & 0.77 \\
\hline Calcium (mg) & $511.25 \pm 210.58$ & $494.85 \pm 189.42$ & 0.51 \\
\hline Fiber (g) & $17.59 \pm 5.35$ & $17.49 \pm 5.18$ & 0.88 \\
\hline
\end{tabular}

Values are presented as mean \pm standard deviation for continuous variables. Sample size is unweighted. Missing data are excluded.

${ }^{*}$ Obtained from $\chi^{2}$ tests for categorical variables and independent $t$-tests for continuous variables. Triglyceride value is log transformed.
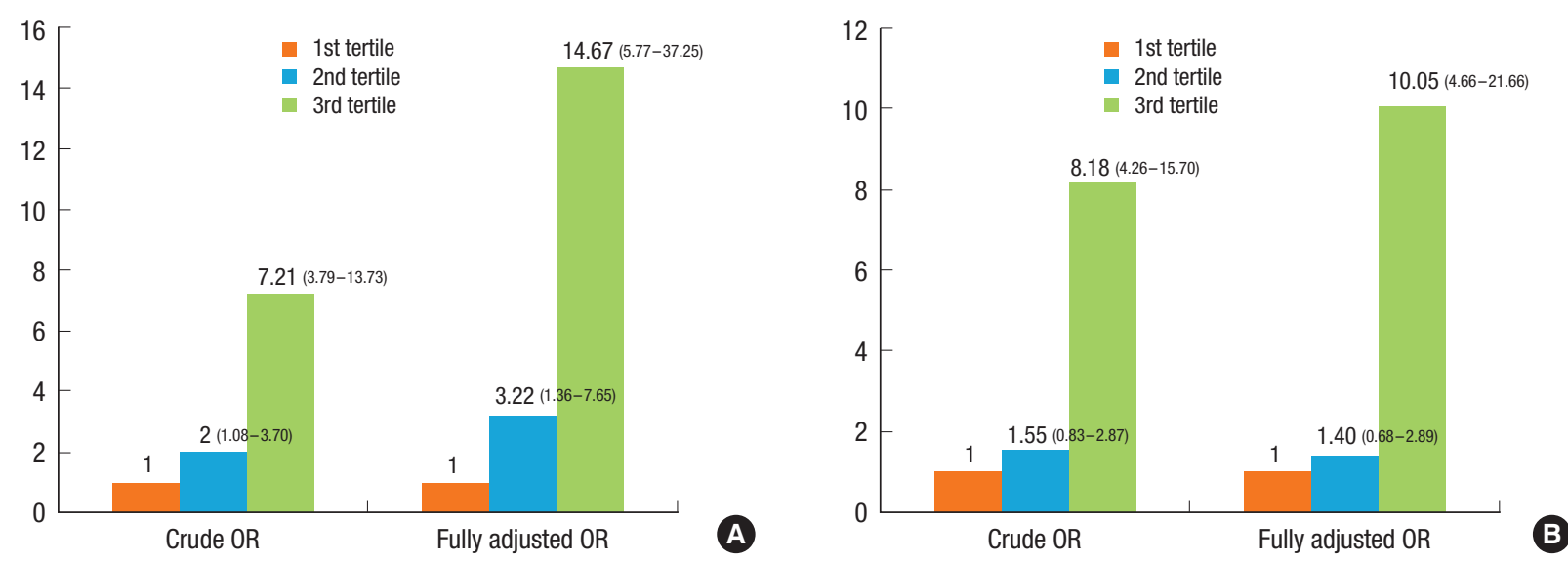

Figure 1. Logistic regression results of (A) fat mass and (B) percent fat. Values are presented as odds ratio ( $95 \%$ confidence interval). Sample size is unweighted. The adjusted model was adjusted for age, sex, socioeconomic status, mother's prepregnancy body mass index, father's obesity, screen time, fruit and vegetable intake, and physical activity. $\mathrm{OR}$, odds ratio.

dren suggest that fat mass and percent fat are associated with MUO in children. These relationships remained significant after adjusting for multiple confounding factors. A subset of obese participants, referred to as MHO, exhibit a better cardiometabolic profile than expected considering their adiposity. ${ }^{11)} \mathrm{Ab}-$ dominal fat distribution, visceral and ectopic fat accumulation, and insulin resistance are crucial features and potential causative factors for the development of MUO in adults, as indicated in a recent study that found significantly higher visceral fat mass in individuals with insulin-resistant obesity independent of BMI and total fat mass, supporting the notion that visceral fat accumulation is a strong and independent predictor of ad- verse health outcomes of obesity. ${ }^{15)}$ We also found that higher fat mass is related to MUO.

A recent Korean study found that women whose mothers worked during their childhood had greater odds of developing metabolic syndrome. In men, however, no significant associations were detected between metabolic syndrome and maternal education level or occupational status. ${ }^{21)}$ We also did not find any noteworthy associations between these factors in our study.

Another study indicated that parental obesity, short sleep duration, low socioeconomic status, and frequent snacking are associated with BMI and BMI changes in Korean children. ${ }^{22)}$ 
This needs to be investigated further. Studies have also shown that low birth weight is associated with impaired insulin resistance and metabolic syndrome later in life. ${ }^{23,24)}$ The mean birth weight was higher in the MHO group than in the MUO group in our univariate analysis, although the difference was not statistically significant.

The major strength of this study is the description of several features of pediatric MHO and MUO. To the best of our knowledge, this is the first study investigating $\mathrm{MHO}$ and related factors in Korean children and adolescents. It was interesting for us to observe a significant association between fat mass/percent fat and MUO status. There already exist a number of wellknown methods to evaluate obesity status, e.g., fat mass, percent fat, and BMI. We suppose the statistical results of our research imply that fat mass, not simply higher weight, plays a key role in MUO in children, a result that provides potential support for further studies on pediatric and adult MHO and MUO.

However, this study must be viewed within the context of its limitations as well as its strengths. First, having only a few hundred final participants in our sample hindered us from estimating accurate statistical values. Second, the cross-sectional study design limited our ability to make inferences about the causal relationships between $\mathrm{MHO}$ and several factors. Reevaluation of cardiovascular risk factors seems appropriate when obese children enter into puberty. ${ }^{18)}$ Further longitudinal studies will be needed in the future. Third, in this study, we did not investigate abdominal fat distribution, visceral and ectopic fat accumulation, or insulin resistance despite that they are crucial features and potential causative factors for the development of MUO. The clinical significance of pediatric truncal obesity is not clear yet in comparison with adults. In addition, we used WC as a criterion to define a metabolically healthy status and thus did not consider it an independent variable. Finally, our research was restricted to Asian children and adolescents aged 8-12, and therefore, our perspective on MHO for other ethnicities and age groups was limited.

In conclusion, our study provides some evidence suggesting that fat mass and percent fat are associated with metabolically healthy phenotypes of obesity among children. Thus, they may represent a useful predictor and intervention target in obese children to enhance healthy traits.

\section{CONFLICT OF INTEREST}

No potential conflict of interest relevant to this article was reported.

\section{ACKNOWLEDGMENTS}

We thank all the participating schools, children, and parents, as well as current and past investigators and staff. This research was supported by grants from the Korea National Institute of Health, Korea Center for Disease Control (2010-E64001-00) and Hallym University Research Fund (HURF-2014-33).

\section{REFERENCES}

1. Bastien M, Poirier P, Lemieux I, Despres JP. Overview of epidemiology and contribution of obesity to cardiovascular disease. Prog Cardiovasc Dis 2014;56:369-81.

2. Bluher M. Are there still healthy obese patients? Curr Opin Endocrinol Diabetes Obes 2012;19:341-6.

3. Phillips CM. Metabolically healthy obesity: definitions, determinants and clinical implications. Rev Endocr Metab Disord 2013;14:219-27.

4. Navarro E, Funtikova AN, Fito M, Schroder H. Can metabolically healthy obesity be explained by diet, genetics, and inflammation? Mol Nutr Food Res 2015;59:75-93.

5. Hankinson AL, Daviglus ML, Van Horn L, Chan Q, Brown I, Holmes E, et al. Diet composition and activity level of at risk and metabolically healthy obese American adults. Obesity (Silver Spring) 2013;21:637-43.

6. Phillips CM, Perry IJ. Does inflammation determine metabolic health status in obese and nonobese adults? J Clin Endocrinol Metab 2013; 98:E1610-9.

7. Dalzill C, Nigam A, Juneau M, Guilbeault V, Latour E, Mauriege P, et al. Intensive lifestyle intervention improves cardiometabolic and exercise parameters in metabolically healthy obese and metabolically unhealthy obese individuals. Can J Cardiol 2014;30:434-40.

8. Hwang LC, Bai CH, Sun CA, Chen CJ. Prevalence of metabolically healthy obesity and its impacts on incidences of hypertension, diabetes and the metabolic syndrome in Taiwan. Asia Pac J Clin Nutr 2012;21:22733.

9. Karelis AD. Metabolically healthy but obese individuals. Lancet 2008; 372:1281-3.

10. Karelis AD, Faraj M, Bastard JP, St-Pierre DH, Brochu M, Prud'homme $\mathrm{D}$, et al. The metabolically healthy but obese individual presents a favorable inflammation profile. J Clin Endocrinol Metab 2005;90:414550.

11. Marini MA, Frontoni S, Succurro E, Arturi F, Fiorentino TV, Sciacqua A, et al. Differences in insulin clearance between metabolically healthy and unhealthy obese subjects. Acta Diabetol 2014;51:257-61.

12. Vukovic R, Mitrovic K, Milenkovic T, Todorovic S, Soldatovic I, SipeticGrujicic S, et al. Insulin-sensitive obese children display a favorable metabolic profile. Eur J Pediatr 2013;172:201-6.

13. Rey-Lopez JP, de Rezende LF, Pastor-Valero M, Tess BH. The prevalence of metabolically healthy obesity: a systematic review and critical evaluation of the definitions used. Obes Rev 2014;15:781-90.

14. Choi MK, Han YA, Roh YK. Utility of obesity indicators for metabolically healthy obesity: an observational study using the Korean National Health and Nutrition Examination Survey (2009-2010). BMC Public Health 2014;14:1166.

15. Bluher M. The distinction of metabolically 'healthy' from 'unhealthy' obese individuals. Curr Opin Lipidol 2010;21:38-43.

16. Bluher S, Schwarz P. Metabolically healthy obesity from childhood to adulthood: does weight status alone matter? Metabolism 2014;63:108492. 
17. Song YH. The association of blood pressure with body mass index and waist circumference in normal weight and overweight adolescents. Korean J Pediatr 2014;57:79-84.

18. Reinehr T, Wolters B, Knop C, Lass N, Holl RW. Strong effect of pubertal status on metabolic health in obese children: a longitudinal study. J Clin Endocrinol Metab 2015;100:301-8.

19. Prince RL, Kuk JL, Ambler KA, Dhaliwal J, Ball GD. Predictors of metabolically healthy obesity in children. Diabetes Care 2014;37:1462-8.

20. Li S, Chen W, Srinivasan SR, Xu J, Berenson GS. Relation of childhood obesity/cardiometabolic phenotypes to adult cardiometabolic profile: the Bogalusa Heart Study. Am J Epidemiol 2012;176 Suppl 7:S142-9.

21. Choi BY, Lee DC, Chun EH, Lee JY. The relationship between metabolic syndrome and childhood maternal education level, job status findings from the Korean National Health and Nutrition Examination, 2007-
2009. Korean J Fam Med 2014;35:207-15.

22. Lee HH, Park HA, Kang JH, Cho YG, Park JK, Lee R, et al. Factors related to body mass index and body mass index change in Korean children: preliminary results from the obesity and metabolic disorders cohort in childhood. Korean J Fam Med 2012;33:134-43.

23. Sipola-Leppanen M, Vaarasmaki M, Tikanmaki M, Matinolli HM, Miettola S, Hovi P, et al. Cardiometabolic risk factors in young adults who were born preterm. Am J Epidemiol 2015;181:861-73.

24. Bouhours-Nouet N, Dufresne S, de Casson FB, Mathieu E, Douay O, Gatelais F, et al. High birth weight and early postnatal weight gain protect obese children and adolescents from truncal adiposity and insulin resistance: metabolically healthy but obese subjects? Diabetes Care 2008;31:1031-6. 